\title{
Effective stiffness of reinforced concrete section with lightweight blocks infill
}

\author{
Ade Sri Wahyuni, Vanissorn Vimonsatit \& Hamid Nikraz \\ Department of Civil Engineering, Curtin University of Technology, Perth, Australia
}

\begin{abstract}
An experimental program has been conducted to explore the potential use of the developed Lightweight Sandwich Reinforced Concrete LSRC section as beam members. The Autoclaved Aerated Concrete (AAC) is used as infill in the LSRC section. Based on the tested beams, the flexural and shear strengths of LSRC beams are found to be comparable with the strengths of the solid beams having identical height. ANSYS 12.1 was employed to develop nonlinear finite element models of LSRC beams. The beams modelled with ANSYS followed the same trend as the actual beam in the elastic range, however after the first cracking the loss of stiffness in ANSYS model caused greater deflection compared to the actual beam. It is obvious that after the first crack the stiffness of sandwich section decrease because the lower elastic modulus of the combined materials. Another investigation is made to compare the behaviour of an LSRC beam with a hollow beam subjected to flexure failure. It is found that the stiffness decreases along with the decrease of the cross section of concrete. The results of the deflections predicted by ANSYS are comparable with the deflection based on the stiffness equation provided by Australian design code.
\end{abstract}

Keywords: lightweight concrete, stiffness, composite section, sandwich section, ANSYS

\section{INTRODUCTION}

Sandwich construction is used in applications where weight is critical. With fillers, the moment of inertia of a sandwich panel increases resulting in a high ratio of bending stiffness to weight. The bending stiffness of a sandwich beam depends on its flexural rigidity and shear rigidity (Gibson 1984). Wittrict (1945) and Ackers (1945) believed that there was an optimum core density which minimized the weight for a given strength of beam. Research by Gibson and Ashby (1982) shows that elastic moduli are linearly related to density when the cell walls deform axially, and they are related to density squared or cubed when the cell walls bended. Furthermore, the stiffness and displacement of reinforced concrete structures are influenced by the crack initiation and propagation of the structures (Kara and Dundar, 2009).

This paper focuses on developing nonlinear finite element model of LSRC beams with ANSYS to determine the loss of stiffness with the decrease of the cross section of the concrete.

\section{LSRC SECTION}

The LSRC section is made up of reinforced concrete filled with prefabricated AAC blocks in the region where the concrete is considered ineffective under bending. The LSRC members have weight saving benefits and are easy to construct due to the lighter weight. The construction method of LSRC members can either fully precast, semi precast or cast in situ.

An experimental program has been conducted to explore the feasibility of using LSRC as a beam member. Three beams were prepared to investigate the flexural of the LSRC i.e solid beam (SB1F), beam with eight AAC blocks infill (LB1F) and beam with four AAC blocks infill (LB2F). Based on the test result, the flexural capacity was found to be almost identical to the capacity of the equivalent solid beam (Vimonsatit et al. 2012). Furthermore, four slabs were constructed, one solid and three LSRC slabs. LSRC beams and slabs during construction are as shown in Figures 1
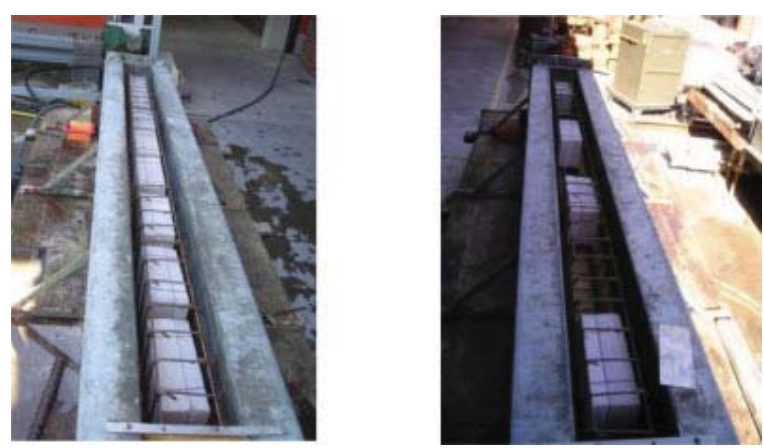

Figure 1. Construction of LSRC beams. 

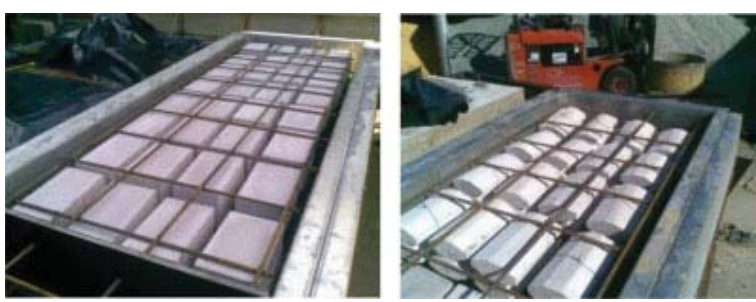

Figure 2. Construction of LSRC slabs.

and 2, respectively. The results show that LSRC slabs exhibit similar behavior to the equivalent solid slab (Wahyuni et al. 2012).

\section{FINITE ELEMENT MODELLING}

The concrete was modeled with solid65, which has eight nodes with three degrees of freedom at each node, i.e., translation in the nodal $\mathrm{x}, \mathrm{y}$, and $\mathrm{z}$ directions. The element is capable of plastic deformation, cracking in three orthogonal directions, and crushing.

A link8 element was used to model the steel reinforcement. This element is also capable of plastic deformation. Two nodes are required for this element which has three degree of freedom, as in the case of the concrete element. Discrete method was applied in the modelling of the reinforcement and stirrups used in the tested specimen. The two elements were connecting at the adjacent nodes of the concrete solid element, such that the two materials shared the same nodes. By taking advantage of the symmetry of the beam layout, only half of the beam in longitudinal direction has been modeled in the finite element analysis.

\subsection{Concrete}

For concrete, ANSYS requires an input data for material properties, which are Elastic modulus $\left(E_{c}\right)$, ultimate uniaxial compressive strength $\left(f_{c}^{\prime}\right)$, ultimate uniaxial tensile strength (modulus of rupture, $f_{r}$ ), Poisson's ratio $(v)$, shear transfer coefficient $\left(\beta_{t}\right)$. The modulus of elasticity of concrete was $32000 \mathrm{MPa}$ which was determined in accordance with AS 1012.17 (1997). Poisson's ratio for concrete was assumed to be 0.2 for all the beams.

The shear transfer coefficient, $\beta_{t}$, represents the conditions of the crack face. The value of $\beta_{t}$, ranges from 0 to 1 with 0 representing a smooth crack (complete loss of shear transfer) and 1 representing a rough crack (i.e., no loss of shear transfer) as described in ANSYS. The value of $\beta_{t}$ specified in this study is 0.4 .

The numerical expressions by Desayi and Krisnan (1964), Eqs. (1) and (2), were used along with Eq. (3) (Gere and Timoshenko 1997) to construct the multilinear isotropic stress-strain curve for concrete in this study.

$$
f=\frac{E_{c} \varepsilon}{1+\left(\frac{\varepsilon}{\varepsilon_{0}}\right)^{2}}
$$

$$
\begin{gathered}
\varepsilon_{0}=\frac{2 f_{c}^{\prime}}{E_{c}} \\
E=\frac{f}{\varepsilon}
\end{gathered}
$$

where:

$f=$ stress at any strain $\varepsilon$

$\varepsilon=$ strain at stress $\mathrm{f}$

$\varepsilon_{o}=$ strain at the ultimate compressive strength $f_{c}^{\prime}$

The concrete used was grade 40 , having the compressive strength of $43.3 \mathrm{MPa}$ at 28 days. The strength value of AAC blocks used in the model was $3.5 \mathrm{MPa}$. The compressive stress at 0.3 of the compressive strength was used as the first point of the multi-linear stress-strain curve.

The crushing capability of the concrete was turned off to avoid any premature failure (Barbosa and Riberio 1998).

\subsection{Steel reinforcement}

All beams were provided with top and bottom longitudinal bars, N20 bars were used as the bottom steel in all beams with tensile strength at yield was $560 \mathrm{MPa}$ while the yield strength of R-bars which was used as the top bar and the stirrup was $300 \mathrm{MPa}$. The steel for the finite element models was assumed to be an elastic-perfectly plastic material and identical in tension and compression. Poisson ratio of 0.3 was used for the steel. Elastic modulus, $E_{s}=200,000 \mathrm{MPa}$.

\section{THE STIFFNESS COMPARISON BETWEEN SOLID AND SANDWICH SECTION}

It is obvious that after the first crack the stiffness of sandwich section decrease because the lower EI of the combine materials. An attempt was made to compare between the sandwich sections with the hollow one, for beam failed in flexure by modeling it with ANSYS. It can be clearly seen that the stiffness decrease along with the decrease of the cross section of concrete. The graph for LSRC beam lay between the solid beam and the hollow one. The lower modulus of elasticity of AAC blocks influences the stiffness of the section.

\section{CORRELATION OF LOAD-DEFORMATION BEHAVIOUR WITH CODE PREDICTIONS}

The four point test was adapted in this study. Figure 4 shows the span and load point arrangement of the tested beams.

In order to predict the load-deformation behavior for beam, the following deflection at midspan equation was used:

$$
\Delta=\frac{P a}{24 E_{c} I_{e f}}\left(3 \ell^{2}-4 a^{2}\right)+\frac{5 w \ell^{4}}{384 E_{c} I_{e f}}
$$




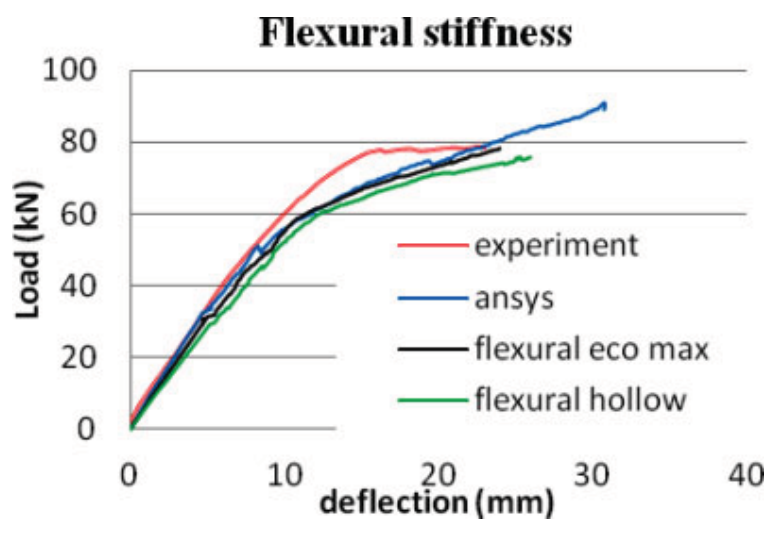

Figure 3. Load versus deflection showing the stiffness of beams.

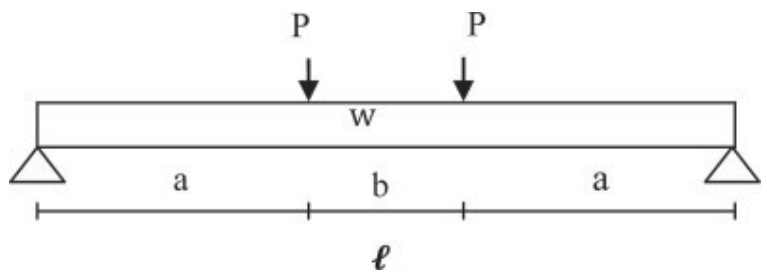

Figure 4. Four-point test arrangement.

where

$\Delta=$ Deflection at midspan ( $\mathrm{mm})$

$P=$ Load applied (N).

$E_{c}=$ Modulus of elasticity of concrete (MPa).

$I_{e f}=$ Effective second moment of area $\left(\mathrm{mm}^{4}\right)$.

$\ell=$ Distance between the two supports ( $\mathrm{mm}$ ).

$a=$ Distance between the load to the nearest support (mm)

$w=$ Uniformly distribution load .

From the code, the formula to determine $I_{e f}$ is given as follows in clause 8.5.3.1:

$I_{e f}=I_{c r}+\left(I-I_{c r}\right)\left(M_{c r} / M^{*}\right)^{3} \leq I_{e \cdot \max }$

where:

$I_{c r}=$ second moment of area of cracked reinforced section

$I=$ second moment of area of the cross-section

$M_{c r}=$ bending moment causing cracking of the section $M^{*}=$ the design bending moment

The second moment of area of cracked reinforced section can be determined using the formula derived from analysis by transformed section. The formula is as follows:

$\begin{aligned} I_{c r}= & \frac{1}{3} b d_{n}^{3}+(n-1) A_{s c}\left(d_{n}-d_{s c}\right)^{2}+ \\ & n A_{s t}\left(d_{n s t}-d_{n}\right)^{2}\end{aligned}$

where:

$A_{s c}=$ the cross-sectional area of compressive reinforcement.
Table 1. Calculated EI Values based on Test Results.

\begin{tabular}{llllll}
\hline Beam & $\begin{array}{l}P_{c r} \\
(\mathrm{kN})\end{array}$ & $\begin{array}{l}P_{u} \\
(\mathrm{kN})\end{array}$ & $\begin{array}{l}E I_{e f} \\
\left(\mathrm{Nmm}^{2}\right)\end{array}$ & $\begin{array}{l}\underline{\Delta} \\
(\mathrm{mm})\end{array}$ & $\begin{array}{l}\Delta_{\text {actual }} \\
(\mathrm{mm})\end{array}$ \\
\hline SB1F & 20.545 & 76.848 & $5.34 \mathrm{E}+12$ & 15.410 & 15.449 \\
LB1F & 23.321 & 79.436 & $5.11 \mathrm{E}+12$ & 16.900 & 17.603 \\
\hline
\end{tabular}

$d_{s c}=$ the distance from the extreme compressive fibre of the concrete to the centroid of the compressive reinforcement.

$d_{s t}=d_{o}$

The moment in the midspan can be calculated by

$M=\left(P+\frac{w \ell}{2}\right) \times \frac{\ell}{2}-\left(P \times \frac{b}{2}\right)-\left(\frac{1}{2} w \frac{\ell^{2}}{2}\right)$

The effective second moment of area $\left(I_{e f}\right)$ of a reinforced concrete beam section after cracking has occurred lies in the range of:

$I_{c r}<I_{e f}<I_{g}$

The sectional stiffness varies according to the following condition:

- If $M<M_{c r}$, the stiffness is $E_{c} I_{g}$

- If $M \geq M_{c r}$, the stiffness is $E_{c} I_{e f}$

Table 1 shows the $E I_{e f}$ values for the tested beams. Equation (5) was used to determine the $I_{e f}$. The $M$ and $M_{c r}$ are derived from equation (7) by referring to the $P_{u}$ and $P_{c r}$ of the beam from the experimental investigation. For solid beam, $w$ (uniformly distributed load) was calculated by multiplied the area of beam cross section with density of concrete $\left(2400 \mathrm{~kg} / \mathrm{m}^{3}\right)$. For LSRC beam, the AAC cross section was multiplied by the AAC density $\left(550 \mathrm{kgm}^{3}\right)$ and adds with the remaining concrete multiplied by its density. The deflection $\Delta$ can be determined after knowing the value of $E I_{e f}$.

Once the crack occurs in concrete, the $E I_{e f}$ in the sandwich section will be influenced by the modulus of elasticity of both concrete and AAC blocks. In this study it is calculated based on the percentage of concrete and AAC blocks volume available in the sandwich section.

The difference of $E I_{e f}$ of the solid beam to LSRC beams is about $4.5 \%$. This hand calculation agrees well with the experimental results.

Based on the assumption used to calculate the stiffness, as described above, the predicted deflection of LSRC beam is lower than the actual deflection obtained from the test results. Further investigations are required to investigate the effect of AAC blocks on the stiffness of concrete section when used as infill in the section. In the present work, the difference between the predicted and the test results is small so the assumption used is considered acceptable. 


\section{CONCLUSION}

The calculation of the effective stiffness of LSRC section is made from the load-deflection relationship from the experimental results. The calculated stiffness is then used to recompute the beam deflection which compares well with the test results. Based on this study the following conclusions are drawn:

1. The stiffness of the beams decrease along with the decrease of the cross section of concrete due to lightweight blocks infill. The difference of the effective stiffness between the tested solid beam and LSRC beam is below 5\%.

2. The results of the deflections from the experimental investigation are comparable with the deflection prediction based on stiffness equations provided by Australian design code.

3. For a more conservative prediction of the deflection of LSRC beams, more works are required to further modify the stiffness equation of a reinforced concrete beams with AAC blocks infill.

\section{REFERENCES}

Ackers, P, 1945. The Efficiency of Sandwich Strut Utilizing a Calcium Alginate Core. $R \& M$ 2015, UK Aeronautical Research Council, Farnborough, Hants.

AS3600 Committee BD-002, 2009. Concrete Structures, Standards Australia.

ANSYS Theory Reference, version 12.1, Swanson Analysis System, available at Curtin University, 2010.
Barbosa, A.F., Ribeiro, G.O, 1998. Analysis of Reinforced Concrete Structures Using ANSYS Nonlinear Concrete Model, Computational Mechanics, pp.1-7,

Desayi, P and Krishnan, S, 1964. Equation for the StressStrain Curve of Concrete, Journal of American Concrete Institute, 61, 345-350.

Gere, J.M. and Timoshenko, S.P. 1997. Mechanics of Materials, PWS Publishing Company, Boston Massachusetts.

Gibson,, L.J and Ashby, M.F, 1982. The Mechanics of ThreeDimensional Cellular Materials. Proc. R. Soc. London, Ser. A, 382, 43-59

Gibson, L.J, 1984. Optimisation of Stiffness in Sandwich beams with Rigid Foam Cores. Material Science and Engineering, 67, 125-135

Kara, Ilker Fatih and Dundar, Cengiz, 2009. Effect of Loading Types and Reinforcement Ratio on an Effective Moment of Inertia and Deflection of a Reinforced Concrete Beam. Advances in Engineering Software (40) 836-846.

Vimonsatit, V., Wahyuni, A.S., Nikraz, H 2012. "The Behaviour Of Lightweight Sandwich Reinforced Concrete Beams, Scientific Research and Essays (accepted for publication)

Wahyuni, A.S., Vimonsatit, V, Nikraz, H 2012. Shear Behaviour of Lightweight Sandwich Reinforced Concrete Slabs, Advances in Structural Engineering (accepted for publication)

Wittrick, W.H, 1945. A Theoretical Analysis of the Efficiency of Sandwich Construction Under Compressive End Load, $R \& M$ 2016, UK Aeronautical Research Council, Farnborough, Hants. 